\title{
HOSPITALIDA DES INCONDICIONAL E CONDICIONAL SEGUNDO JACQUES DERRIDA: fundamentos filosóficos e aplicações teológicas
}

Ramiro Délio Borges de Meneses ${ }^{1}$

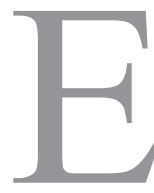

STE ARTIGO REVISA AS NOÇÕES DE HOSPITALIDADE INCONDICIONAL -enquanto exposição à vinda daquele que vem-e de hospitalidade condicional -enquanto lógica do convite- oferecidas pelo trabalho de desconstrução feito por Jacques Derrida em De l'hospitalité. Presenta deste modo seus fundamentos filosóficos e as aplicações teológicas procurando estabelecer, primeiro, a relação de indissociabilidade entre as duas noções mas também suas particularidades e, segundo, as relações com a ética e com a cidadania.

Palabras clave: Jacques Derrida, Hospitalidade Incondicional, Condicional e Outro.

\section{THE INCONDITIONALAND CONDITIONAL HOSPITALITIES ACCORDING TO JACQUES DERRIDA: philosophical foundations and theological applications.}

The following article reviews both notions of inconditional hospitality -as an exposition to the coming of the one who comes- and of conditional hospitality -as logic of invitation- offered by the work of Jacques Derrida in De l'hospitalité. Thus the article presents its philosophical foundations and its theological applications aiming

1 Doutor em Filosofia (especialidade em Éticas Aplicadas) e Professor Auxiliar no Instituto Superior de Ciências da Saúde do Norte, CESPU, Gandra, PORTUGAL; Membro Integrado do Centro de Estudos Filosófico-Humanisticos, Faculdade de Filosofia, Centro Regional de Braga, Universidade Católica Portuguesa; Correo electrónico: borges272@gmail.com 
at establishing, first an indissociable relation between the two notions, but also their corresponding particularities, and second, their relations to ethics and citizenship.

Keywords: Jacques Derrida, Conditional and Unconditional hospitalities, and the Other

\section{INTRODUÇÃO}

A hospitalidade incondicional é inseparável da hospitalidade condicional. Aquela fundamenta esta. É mesmo assim numa tal indissociabilidade e faz com que a hospitalidade incondicional, que não tem qualquer estatuto legal, aconteça modificando as condições da hospitalidade. É uma indissociabilidade que traduz o movimento de ação, inscrição, transgressão e perversão da própria hospitalidade incondicional na hospitalidade condicional, bem como da heteroafeção, interrupção, transformação e contaminação. Porém, a hospitalidade condicional é uma visita por convite entre um anfitrião e um estrangeiro. Trata-se, pois, segundo Derrida, de uma hospitalidade por convite. É uma forma de hospitalidade que se fundamenta na hospitalidade incondicional ${ }^{2}$. Podem, também, entender-se como sinónimos uma da outra. Naturalmente é uma hospitalidade condicionada pelo direito de asilo, pelo direito à inimização da cidadania e, mesmo ainda, pelo direito universal. Será aquilo que diz Derrida, quando salienta que só uma hospitalidade incondicional poderá dar sentido e referir a racionalidade prática do conceito de acolhimento ${ }^{3}$. A hospitalidade condicional, para Derrida, sustenta-se como hospitalidade de direito. A cidadania, também, se apresenta como uma hospitalidade de direito, porque se situa fenomenologicamente como sendo uma hospitalidade condicional, como analizaremos ao longo deste estudo.

Pensar a hospitalidade, segundo Derrida, significa pensar esta possibilidade sem condições. Entretanto, a lei incondicional da hospitalidade, uma lei pré-ética e pré-jurídico-política é impossível, como tal, e impossível de deixar-se acolher na língua e nas leis da hospitalidade sempre se perverta. Logo, o hóspede, na figura do visitante ou do Outro absoluto, que é acolhido, pode trazer com ele, tanto o bem,

2 Cf. CHÉRIF, M, Islam et l'Occident, rencontre avec Jacques Derrida. Odile Jacob, Paris, 2006, pp.143144.

3 Cf. DERRIDA, J, Voyous, Deux essais sur la raison, Éditions Galilée. Paris, 2003, pp. 204-205. 
quanto o mal; tanto a amizade, quanto a violência. Desta feita, a "aporia" reside justamente pelo facto de que há um domínio irreconciliável, expresso como A lei, singular, universal e, ao mesmo tempo, as leis, particulares e condicionais. Contudo, a possibilidade da hospitalidade será sustentada pela im-possibilidade. Para que a hospitalidade incondicional seja viável, é necessário compreendê-la através da perspetiva desconstrutora de uma ultrapassagem das oposições binárias metafísicas, como comenta Maia Soares ${ }^{4}$.

A hospitalidade parece ir de impossibilidade em impossibilidade, porque é um "passo". Como descreve Derrida, qual o significado deste "passo" a mais e a transgressão, se, tanto para o "convidado" (invité), quanto para o "visitante" (visiteur), a passagem do limiar é sempre um passo de transgressão. Deve mesmo sê-lo? Aonde levam estes estranhos processos da hospitalidade? Estes limiares intermináveis, infranqueáveis e estas aporias como se apresentam? Tudo se passa como se fossemos de dificuldade em dificuldade. Melhor ou pior, e mais gravemente, de impossibilidade em impossibilidade passa-se como se a hospitalidade fosse o impossível, como se a lei da hospitalidade definisse esta impossibilidade, como se o imperativo categórico da hospitalidade procurasse transgredir todas as leis da hospitalidade, isto é, as condições, as normas, os direitos, os deveres, que se impõem aos hóspedes e aos hospitantes, aqueles ou aquelas que oferecem ou que recebem o acolhimento. Reciprocamente, tudo se passa como se as leis da hospitalidade consistissem em marcar os limites, os direitos e os deveres, ao defender e ao transgredir a lei da hospitalidade, aquela que permite oferecer, ao que chega, ao "recém-chegado" (arrivant), um acolhimento sem condições. Diremos "sim" ao "recém-chegado", antes de toda a determinação, antes de toda a antecipação, antes de toda a identificação, tratando-se ou não de um estrangeiro, de um imigrado, de um convidado ou de um visitante inopinado, que o "recém-chegado" seja ou não o cidadão de um outro pais, um ser humano, animal ou divino, um vivente ou um morto, masculino ou feminino 5 .

O Outro, incondicionalmente acolhido, antes e para além do próprio dever ético, do direito e do dever de asilo, é um sujeito de direito. Com efeito, será o absoluto da sua estranheza que, na linha de Derrida, distingue o novo "recém-chegado", isto é,

4 Cf. MAIA SOARES, Victor Dias, "Hospitalidade e Democracia por-vir a partir de Jacques Derrida", Ensaios Filosóficos, 2, 2012, p.177.

5 Cf. DERRIDA, Jacques, ’De L'Hospitalité - fragments”, in: Écarts del'Tdentité, 8, 854,1998, p.4. 
a figura sem figura do Outro-absoluto, do estrangeiro, do imigrante, do desvalido no caminho e da vida, do deportado, do refugiado, etc. O "recém-chegado" é acolhido a partir de si próprio, enquanto for um "Outro-absoluto", como secreto, irredutível, incalculável ou indecidível. O acolhimento da sua incerteza, a "abertura" ao inesperado da sua vinda, é, para Derrida, a "ética como hospitalidade". Seja uma lei que dita o tom à hospitalidade incondicional, que Derrida também designa de pura, justa, infinita, impossível e absoluta. Segundo Maia Soares: “ a hospitalidade de forma incondicional, de facto que não existe. A sua impossibilidade acaba-se desdobrando no contexto de uma democracia por-vir que, em si mesma, é problemática. A noção de democracia por-vir, para Derrida, pertence ao tempo da promessa e está inscrita num processo sem fim de melhoramento e de perfetibilidade , estando sempre "porvir" Tal como a democracia, assim também a cidadania parece estar "por-vir". Está sempre in fieri.

Mas, Derrida considera que a hospitalidade absoluta (incondicional) determina que eu abra a minha casa, "chez-moi", e que me dê não apenas ao estrangeiro (dotado de um nome de família, de um estatuto social de estrangeiro, etc.), mas também ao Outro-absoluto, desconhecido, sem nome, e que lhe dê lugar, que o deixe vir, que o deixe chegar, ter lugar no lugar, que lhe ofereça, sem lhe pedir reciprocidade ( a entrada num pacto), sem mesmo lhe perguntar pelo nome ${ }^{7}$. Como salienta Fernanda Bernardo, a hospitalidade incondicional será então aquela que antes e para além do ser, do ter, do saber, do poder e do querer ao Outro singular, não será já determinada ao cidadão estrangeiro, ou seja, em termos jurídico-políticos, mas como um Outro Absoluto. Será, naturalmente, uma hospitalidade trans-económica, trans-auto-nómica. Assim, em Derrida, a hospitalidade incondicional expõe-se, sem limites, na vinda do Outro, para além do direito, para além da hospitalidade condicionada pelo direito de asilo, pelo direito à imigração, pela cidadania e, ainda, pelo direito à hospitalidade universal, de que fala Kant e que permanece controlada por um direito cosmopolita. Só uma hospitalidade incondicional pode clarificar o seu sentido e a sua racionalidade prática. A hospitalidade incondicional ultrapassa o cálculo jurídi-

6 Cf. MAIA SOARES, V. D, ”Hospitalidade e Democracia por-vir a partir de Jacques Derrida”, pp.177178.

7 Cf. DERRIDA, J, De l'hospitalité, Anne Dufourmantelle invite Derrida à répondre. Calmann-Levy, Paris, 1977, p.29. 
co, a política ou a economia. Mais nada, nem ninguém chega a ela ${ }^{8}$. A hospitalidade incondicional é uma relação de relações meta-autonómicas e metaeconómicas.

Segundo a perspetiva de Derrida, há hospitalidade quando eu acolho mais do que aquilo que posso acolher, quando acolho para além da minha capacidade. A hospitalidade incondicional não é senão exposição à chegada daquele que vem, do que acolhe. Será uma hospitalidade que dá aquilo que não tem, aquilo que não possui como próprio. É uma hospitalidade como impossível. Faz o impossível e é não apenas impossível, como um convite a fazer aquilo que é impossível. A hospitalidade absoluta exige que me abra ao meu próprio existir "chez moi" (minha casa) e que me ofereça não somente ao estrangeiro, como também ao Outro-absoluto, desconhecido, anónimo, e que lhe dê lugar, que o deixe vir, que o deixe chegar e ter um lugar no lugar, que lhe ofereça, sem the pedir reciprocidade, nem mesmo através do seu nome 9 .

A lei da hospitalidade incondicional manda acolher incondicionalmente, ou seja, o visitante ou o Absoluto que chega. A esta forma de hospitalidade, Derrida designa como "hospitalidade de visitação", contraposta à hospitalidade condicional ou normativa, que obedece à lógica do convite. Com Marta e Maria, em Betânia, houve uma "visitação" de Jesus Cristo. Cristo, segundo a Teologia, foi a "visitação" de Deus-Pai, tal como se narra em Jo 1,14. Assim pensa Derrida sobre este acolhimento: "a hospitalidade pura e incondicional, a própria hospitalidade abre-se, está antecipadamente aberta a quem não é nem esperado, nem convidado, a quem chegue como visitante, absolutamente estrangeiro, como chegante não identificável e imprevisível, como totalmente Outro. Chamemos a isso hospitalidade de visitação e

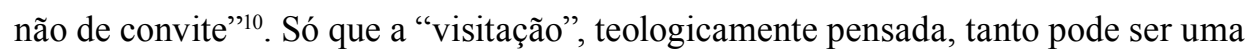
hospitalidade incondicional como uma condicional. A lei da hospitalidade ordena o acolhimento imediato e incondicional do Outro como Outro absoluto e, no seu rasto, de todo e qualquer Outro,sem lhe ditar, como refere Fernanda Bernardo, qualquer

8 Cf. DERRIDA, J, Voyous, Deux essais sur la raison, pp. 204-205.

9 Cf. DERRIDA, J, De l' hospitalité, Anne Dufourmantelle invite Derrida à répondre, p.29.

10 Cf. DERRIDA, J; HABERMAS, J, Le concept du 11 septembre. Éditions Galilée, Paris, 2004, p.188. 
integração, assimilação ou apropriação. Será este acolhimento de todo e qualquer Outro, no acolhimento do Outro-absoluto, que constitui uma "ética da hospitalidade", a sua im-possibilidade, aquele que marca o rítmo e o sentido da desconstrução. $\mathrm{O}$ conceito de hospitalidade pura, incondicional, não tem qualquer status político ou legal, dado que nenhum Estado pode redigi-lo legalmente. Tal hospitalidade é, na prática, impossível de ser organizada. Esta hospitalidade incondicional, nem jurídica, nem política, é ainda assim a própria condição do político e do jurídico. Nesta perspetiva, poderíamos questionar se uma hospitalidade condicionada, imune ao totalmente Outro, que chega, sem riscos, seria verdadeiramente hospitalidade. Para Derrida, as hospitalidades (condicional e incondicional) poderiam mesmo conduzir a uma perversão da própria Ética. Logo, será necessário condicionar essa incondicionalidade, organizando essa hospitalidade, o que significa a criação das leis, direitos e convenções.

A hospitalidade é, segundo Derrida, "par coeur". Para Fernanda Bernardo, a fim de que se rasgue o escrito e se aprenda de cor, na perspetiva de Derrida, o "poema", tal como é sabido, o filósofo faz questão de distinguir da poesia, a qual será sempre a sua catástrofe, porque ditada pelo Outro, pela visitação de uma singular perda de folego, de registo do canto ou "par cour" do saber e, portanto, do registo, tanto quanto do traumatismo do evento. O verdadeiro sentido desta "hospitalidade de visitação" (hospitalidade incondicional) é declarado por Derrida, da forma seguinte: aquele que poderíamos chamar de "recém-chegado" e, o mais chegante entre os chegantes, o que chega por excelência, é aquilo, aquele ou aquela que, mesmo ao chegar, não passa um limiar, que separaria dois lugares identificáveis, o próprio e o estrangeiro, o próprio de um e o próprio de outro, como se diria que um cidadão de um certo país identificável passa a fronteira de um outro país, como se fosse um viajante, um emigrado ou um exilado político, um deportado ou um refugiado, um trabalhador imigrado, um estudante ou um investigador, um diplomata ou um turista. Estes são recém-chegados, mas a um país que já se determina e cujo habitante, que se sabe ou se crê em sua casa, quer em relação à hospitalidade universal, quer ao direito de visita.

$O$ recém-chegado absoluto não tem ainda, nem nome, nem identidade.E como recém-chegado não tem ainda identidade, o seu lugar de chegada encontra-se, também, des-identificado; não se sabe ainda ou não se sabe mais como chamar, qual é o país, o lugar, a nação, a família, a língua, o em si que acolhe o recém-chegado 
absoluto $^{11}$. Jesus Cristo, em Betânia, representa uma hospitalidade incondicional. Foi uma hospitalidade ad intra et ad extra simultaneamente. A hospitalidade incondicional será uma "visitação elpídica", porque além de ser o alimento da alma (esperança) é a "espera soteriológica", que tem o seu proémio no conto exemplar do Bom Samaritano (Lc 10,25-37). Jesus Cristo, como Hóspede, sem ser por convite, é a "visitação elpidofânica" do Pai das Misericórdias. O Samaritano representou uma hospitalidade extrínseca (ad extra). A relação com o Outro, ut sic, protegida pela alteridade absoluta, é, na sua retidão, uma relação de interrupção como relação infinita. Será uma interrupção devida à alteridade absoluta do Outro que, sendo separado e intangível, nunca se dá à representação ou à compreensão $0^{12}$. Não se deixa tocar pelo Outro, será um contacto sem contacto.

Naturalmente, a Ética, como Hospitalidade, a da hospitalidade, é apenas possível como "hos (ti) - pitalidade", tal como indica Fernanda Bernardo ${ }^{13}$. A relação, para Derrida, uma relação contraditória, aporética, como se visualiza pela lei da hospitalidade, é similar àquela que é própria do sujeito perante a lei. Perante esta lei, o "recém-chegado" não é recebido como hóspede, se não beneficiar do direito à hospitalidade ou direito de asilo. Sem este direito, ele não pode introduzir-se em minha casa, na "casa própria" do hóspede, senão como parasita, hóspede abusivo, ilegítimo, clandestino, passível de expulsão ou de prisã ${ }^{14}$. A lei da hospitalidade, aquela que descreve o sim incondicional ao apelo do Outro, está antes e acima das leis da hospitalidade, melhor, está antes, acima, fora e por diante das leis da hospitalidade, tal como a lei está antes, diante e por diante do homem, que, todavia, terá de a instituir ${ }^{15}$.

Como descreve Derrida, a lei está acima das leis. É portanto ilegal, transgressiva, fora da lei, assim como uma lei anómica, nomos a-nomos, lei acima das leis e lei fora da lei (anomos, lembremos, é assim que, por exemplo, se caracteriza Édipo, o pai-filho, o filho como pai, pai e irmão das suas filhas). Mas situando-se embora

11 Cf. DERRIDA, J, Aporias. Morir-esperase (en) los limites de la verdad. Paidós, Barcelona, 1998 , p.67.

12 Cf. DERRIDA, J, Le toucher Jean-Luc-Nancy, Éditions Galilée, Paris, 2000, p.83.

13 Cf. BERNARDO, F, "A etica da hospitalidade ou o por-vir do cosmopolitismo por-vir. (I.)”, Revista Filosófica de Coimbra, 10, 20, 2001, p.378.

14 Cf. DERRIDA, J, De l'hospitalité, Anne Dufourmantelle invite Derrida à répondre. Calmann-Levy, Paris, 1977, p.57.

15 Cf. Ibidem, pp.71-73. 
acima das leis da hospitalidade, a lei incondicional da hospitalidade tem necessidade das leis, requere-as. Esta exigência é construtiva. Ela não seria efetivamente incondicional, a lei, se não devesse tornar-se efetiva, concreta, determinada, se tal não fosse o seu ser como deve-ser. Ela correria o risco de ser abstrata, utópica, ilusória, e, portanto, de se tornar no seu contrário. Para ser o que é, a lei tem necessidade das leis que, no entanto, a negam, a ameaçam em todo o caso, por vezes a corrompem ou a pervertem. E devem sempre poder fazê-1o ${ }^{16}$. A lei da hospitalidade é, portanto, o ter de se inscrever nas leis do direito da hospitalidade, daqui que ela se apresenta como a própria hospitalidade, como Ética da Hospitalidade, uma lei que é paradoxal. A hospitalidade incondicional é transcendente em relação ao político, ao jurídico e, talvez, até mesmo ao ético. Contudo, aqui está a indissociabilidade, não posso abrir a porta, não posso expor-me à chegada do Outro e oferecer a ele ou a ela o que quer que seja, sem tornar essa hospitalidade efetiva, sem, de certo modo concreto, dar-lhe algo determinado. Aquilo que permanece incondicional ou absoluto arrisca-se a ser nada, caso as condições não consigam fazer alguma coisa, segundo Derrida.

Poderemos dizer, com Derrida, que a hospitalidade absoluta exige que eu abra a "minha casa" (chez moi) e que eu me dê não apenas ao estrangeiro, mas ao Outro absoluto, desconhecido, anónimo, e que eu lhe dê lugar, que o deixe vir, que o deixe chegar e ter lugar no lugar, que lhe ofereço, sem lhe pedir nem reciprocidade (a entrada num palco) com a hospitalidade de direito, com a lei ou a justiça como direito $^{17}$. Com efeito, a hospitalidade pura ou absoluta, imediata, incondicional e infinita, como acolhimento do Outro, do visitante ou do hóspede inesperado, ordena uma rutura, uma rutura que é uma perversão. Assim surgiu uma inquietação ou uma "solicitude em Betânia". Esta é uma rutura com a diaconia de Marta e uma "afirmação pística" pela "audição da palavra" com Maria. Segundo Derrida, a hospitalidade absoluta ou incondicional supõe uma rutura com a hospitalidade, em sentido corrente, com a hospitalidade condicional, como direito, como pacto de hospitalidade. A lei da hospitalidade, a lei formal que governa o conceito geral de hospitalidade, aparece como uma lei aporética. Ela parece ditar que a hospitalidade absoluta rompe com a lei da hospitalidade, como direito ou como dever, como pacto de acolhimento.

16 Cf. Ibidem, pp.73-75.

17 Cf. Ibidem, p.29. 
A hospitalidade justa rompe com a hospitalidade de direito, não que ela a condene ou que se lhe oponha. Com efeito, ela pode mesmo e, ao contrário, mantê-la num incessante movimento de progresso, mas é-lhe tão estranhamente heterogénea, quanto a justiça é heterogénea ao direito, de que, no entanto, tão próxima é e, na verdade, indissociável. A hospitalidade incondicional é uma rutura, uma rutura ao acolhimento do Outro e do anfitrião. Será sempre uma perversão ou uma aceitação. A aceitação interior é o centro do acolhimento do Outro. A hospitalidade absoluta é uma "aceitação agápica" do Outro, por isso é uma rutura doativa do Eu, tal como foi a de Betânia. Também surgiu, no Samaritano, uma "rutura cairológica", quando "acolheu esplancnofanicamente" o Desvalido no Caminho (Lc10,33). É uma hospitalidade entre hóspedes, onde cada um é, na perspetiva de Derrida, "chez soi, chez l'autre" (em sua casa, em casa do Outro). É aquele que a partir da incondição do hóspede acolhido, por aquele mesmo, que ao "acolher" sabe acolher, sabe dizer "sim vem" ao recém-chegado ou ao visitante inesperado, que vem antes de qualquer identificação. Trate-se, pois, ele ou não de um estrangeiro, de um imigrado, de um convidado ou de um visitante inopinado, que o visitante seja ou não o cidadão de um outro país, um ser humano ${ }^{18}$. Toda a hospitalidade explicita-se numa semântica ética, a qual professa uma leitura interpretativa sobre a ética. Naturalmente, o conjunto de direitos e de deveres da cidadania podem expressar-se e ter a sua mundividência na hospitalidade. Toda a hospitalidade condicional é uma cidadania,mas nem toda a cidadania se descreve e vive como hospitalidade condicional, porque a "cidadania da cidadania", quanto ao fundamento filosófico, é uma hospitalidade incondicional. O mesmo não se passa nas suas aplicações teológicas e ontológicas.

\section{2}

A forma de hospitalidade pura, sem a qual não existem conceitos de hospitalidade, vai além da passagem das fronteiras de um país, mas ela tem um papel, também, na vida corrente : quando qualquer um chega, quando o amor chega, por exemplo, ou admite um risco, então estamos expostos. Será necessário manter este horizonte sem horizonte, esta limitação da hospitalidade incondicional, sabendo mesmo que não poderemos elaborar um conceito político e jurídico. Não há lugar para este tipo de

18 Cf. Ibidem, pp.72-73. 
hospitalidade no direito e na politica ${ }^{19}$. Criticamente, existem algumas imprecisões terminológicas, na divisão da hospitalidade, segundo Derrida, porque existem formas puras de hospitalidade, que o pensador-filósofo considera como impuras, como será o caso da narrativa dos discipulos de Emaús. Também, não será correto considerar a hospitalidade de visitação, como incondicional, visto que este equivoco se desfaz igualmente na narrativa de Emaús (Lc 24,13-35). A hospitalidade de Emaús, sendo de convite, não pode ser impura. É, sim, o exemplo de uma hospitalidade pura, dado que Jesus Cristo já estava na anabasis (Ressurreição). Teologicamente pensando, a "hospitalidade de visitação" tanto serve a condicionalidade, quanto a incondicionalidade, uma vez que o verbo latino visitare significa : vir ver, inspeccionar, ver como se está a fazer, por caridade, por dever e/ou por .deferência. Naturalmente, a hospitalidade de visitação é condicional, como manifestamente se descreve em Teoloia Bíblica. Toda a hospitalidade absoluta é uma anabasis. A hospitalidade pura, segundo Derrida, acolhe o Outro, como Outro-absoluto e, acolhendo o Outro como Outro-absoluto, obriga-se, igualmente, a acolher todo e qualquer Outro, porque "tout autre est tout autre" (totalmente outro). A hospitalidade incondicional ou absoluta tem um princípio: proteger o "chez-soi" (em sua casa) por meio de um acolhimento efetivo, como se descreve em Papier Machine, revelando-se, assim, como "acolhimento do acolhimento" ${ }^{20}$. As duas formas de hospitalidade não se contradizem. São, na verdade, complementares. A hospitalidade ética é aquela que acolhe poieticamente, de forma incondicional, o Outro e realiza este "acolhimento de acolhimento", vendo-se nesta uma excelência e o paradigma do acolhimento de todo e qualquer Outro. Com efeito, uma tal hospitalidade será não somente imediata, incondicional, mas, sobretudo, ilimitada, como infinita que é. Contudo, a iminência desta hospitalidade pura, deste acolhimento do Outro, tem "riscos", tal como é afirmado por Derrida $^{21}$. A hospitalidade ética, imediata, incondicional e infinita não pode, nem deve ser outra coisa, senão uma exposição ao risco, como se indica em Papier Machine ${ }^{22}$.

19 Cf. DERRIDA, J; ROUDINESCO, E, De quoi demain,... Dialogue. Éditions Galilée, Paris, 2001, pp.101-102.

20 Cf. Ibidem, p. 273.

21 Cf. Ibidem, p.274.

22 Cf. DERRIDA, J, Papier Machine. Éditons Galilée, Paris, 2001, p.275. 
"Quando abro a minha porta a alguém, será necessário que esteja preparado para correr um maior risco", assevera Derrida ${ }^{23}$. Não sei quem entra pela minha porta dentro. Desconheço, depois conhecem-se ... Aqui reside a estranheza da hospitalidade. O risco da hospitalidade é "elpídico", tem esperas e esperanças, dado que implica uma inevitável dimensão positiva e, uma vez que, para além da subtração ao programa e da exigência da vigília e da constante inovação, encontra-se, naturalmente, na origem da constituição da subjetividade do sujeito. Daqui ser possível dizer que o acolhimento do Outro não se expõe apenas ao risco da agressão e da desordem. Em Betânia houve, com a hospitalidade, o risco inerente da "solicitude" de Marta, ao chamar à atenção de Jesus para o facto de Maria não a ajudar nas tarefas da casa (contra-dons). Será, também, uma oportunidade dada ao hóspede e não ao sujeito soberano, para aceder ao seu próprio risco. O "risco elpídico" torna a hospitalidade como um "acolher elpidofânico" (acolhimento pela esperança), tal como se viveu em Betânia. O hóspede-acolhedor pode, em nome da Ética, decidir revoltar-se contra a condicionalidade das leis da hospitalidade, levado pela sua perfetibilidade. Deve haver uma hospitalidade sem reservas, que se denomina hospitalidade incondicional ${ }^{24}$. As leis condicionais deixariam de ser leis da hospitalidade, se não fossem guiadas, inspiradas, requeridas pela lei da hospitalidade incondicional, como diz Fernanda Bernardo $^{25}$. Na verdade, Derrida diz que a lei da hospitalidade absoluta é, também, uma lei universal de singularidades, um direito à singularidade e à alteridade absolutas, não apenas porque o segredo é respeitável, mas porque ali mesmo, onde se o quisesse violar, ali mesmo onde se pretendesse ter o direito de o não respeitar, ele permanece inacessível, o segredo permanece secreto, há segredo. Aqui reside o segredo da hospitalidade ${ }^{26}$. Em Betânia, houve muitos segredos, visto que "ouvir o hóspede" impõe segredos. A hospitalidade incondicional será segredo e tem segredos.

A lei da hospitalidade incondicional convida ao acolhimento sem reservas e convida ao "acolhimento incondicional" do visitante, do recém-chegado ou da singularidade absoluta. A hospitalidade incondicional impõe segredos e pausas, tais como os veri-

23 Cf. DERRIDA, J, Manifeste pour l'hospitalité. Éditions Paroles d'Aube,Paris, 1999, p.137.

24 Cf. DERRIDA, J, Papier Machine, p.297.

25 Cf. BERNARDO, F, "A etica da hospitalidade ou o por-vir do cosmopolitismo por-vir. (I.)", Revista Filosófica de Coimbra, 10, 20, 2001, pp.391-392.

26 Cf. BERNARDO, F, "Para além do Cosmopolitismo kantiano: Hospitalidade e "altermundialização" ou a Promossa da "nova Inter-nacional" democrática de Jacques Derrida, Revista Portuguesa de Filosofia, 61, 3-4, 2005, p.995. 
ficados na narrativa midráshica dos discípulos de Emaús (Lc24,15-31). Aqui temos uma aplicação bíblica da hospitalidade de carácter etiológico.

A hospitalidade é silêncio. A lei da hospitalidade incondicional, pelo pensamento de Derrida, expressa um convite ao "acolhimento incondicional" do visitante, do chegante ou da singularidade absoluta, revelando-se na "contemplação", que é uma orientação para questionar as leis da hospitalidade condicional. A hospitalidade é uma "contemplação do acolher". Esta contemplação é uma forma de dizer que a hospitalidade é uma linguagem e, naturalmente, para Derrida é um "acolher teórico ", desde a sua etimologia até à mundividência, como se poderá identificar nas aporias, dado que a hospitalidade é a essência da cultura. Todavia, devemos dizer que a hospitalidade vive da cultura e da inculturação. Assim, a hospitalidade é um "poema", que conduz à "interioridade do outro". Daqui se define que a hospitalidade, segundo a nossa perspetiva, é uma "representação acolhedora" de forma biunívoca, indo de dentro para fora (anfitrião) e de fora para dentro (Outro-estranho).

A hospitalidade implica um movimento centrípeto e um centrifugo, intersubjetivamente considerado, como movimento de corações. A lei da hospitalidade absoluta manda romper com a hospitalidade justa, com a hospitalidade do direito, não que a condena, mas será "homogénea", quando a justiça é heterogénea ao direito, de tal maneira que é próxima e indissociável ${ }^{27}$, como Derrida justifica $^{28}$.A hospitalidade manifesta-se como o exterior no interior, será o exterior da casa no interior da mesma. Derrida salienta que a questão da hospitalidade é, necessariamente, "a questão da questão", sendo a questão do sujeito e do nome. Assim, a hospitalidade consistirá em, ela própria, interrogar o "recém-chegado". Começará esta pela pergunta endereçada àquele que vem. Como é que te chamas? Diz-me o teu nome? Ou a hospitalidade dá-se antes, dá-se ao Outro, antes mesmo de ele se identificar, antes mesmo de ele ser sujeito, sujeito de direito e sujeito nomeável pelo nome de família, segundo o pensamento de Derrida.

Em Betânia, a hospitalidade deu-se muito antes de o Outro-estranho (Jesus Cristo) se ter identificado, logo, na entrada, no castellum (Lc 10,38). Como pensa Fernanda Bernardo, se, na sua incondicionalidade, a Lei da Hospitalidade, que convida ao

27 Cf. DERRIDA, J, De l' hospitalité, Anne Dufourmantelle invite Derrida à répondre, p.29.

28 Cf. Ibidem, p.31. 
"acolhimento incondicional" do singular, é, por si própria, uma infinita injunção para o repensar tanto do direito ( nacional e internacional), quanto do político no rumo de uma outra concepção dos mesmos, uma concepção altermundialista e estruturalmente desligada do campo nacional. Mas, Derrida esclarece este sentido da hospitalidade ao dizer que esta, sob a forma incondicional, é transcendente em relação ao político, ao jurídico e, até mesmo, ao ético. Toda a hospitalidade incondicional é uma hospitalidade meta-ética. Mas, eu não posso abrir a porta, expor-me à vinda do Outro e dar-lhe seja o que for sem tornar esta hospitalidade, sem oferecer concretamente qualquer coisa de definido. Uma tal determinação deve, naturalmente, reinscrever o incondicional. O que permanece incondicional ou absoluto arrisca-se a não ser nada, se as condições não fizerem qualquer coisa, para que tal não aconteça ${ }^{29}$. Este soberano bem é, na perspetiva de Derrida, a hospitalidade. Esta revela-se no "acolhimento". A retidão do acolhimento ou da relação ao Outro faz com que o dito sujeito-emissor-hóspede-acolhedor seja, na sua singularidade, um sujeito dividido, como refere Fernanda Bernardo. A hospitalidade “deixa lugar ao outro". O outro está em mim, antes de mim: o ego implica a alteridade como sua condição. Assim, não sou dono de mim, do lugar aberto à hospitalidade, quem dá hospitalidade deve saber que não é sequer proprietário daquilo que parece poder dar. O mesmo pode dizer-se da assinatura, que muitas vezes é vista como marca própria, mas que é aquilo de que nunca posso apropriar-me $\mathrm{e}^{30}$.

A hospitalidade é uma "Gabe" (dom), que se desdobra em "Aufgaben" (tarefas), em virtude da "Vergabe" (entrega). O hóspede entrega-se incondicionalmente ao anfitrião e vice-versa. O anfitrião faz-se hóspede e o hóspede faz-se anfitrião, sem perderem a identidade. O hóspede recebe-se no coração do anfitrião e vice-versa, tal como se realizou em Betânia. Jesus Cristo tornou-se o anfitrião. Pelo pensamento de Derrida, a nossa questão é sempre a identidade. E antes da identidade do sujeito, o que é a ipseidade? Esta não se circunscreve a uma capacidade abstrata para dizer "eu", que terá sempre precedido. Quer dizer talvez, o poder de um "eu posso", mais originário do que o "eu", numa cadeia em que o pse de ipse não se deixa mais desligar do poder do domínio ou da soberania do hospes, como refere Derrida, pela

29 Cf. BERNARDO, F, "Para além do Cosmopolitismo kantiano: Hospitalidade e "altermundialização" ou a Promossa da "nova Inter-nacional" democrática de Jacques Derrida ”, p.1004.

30 Cf. DERRIDA, J; FERRARIS, M, O Gosto do Segredo, Tradução de Miguel Serras Pereira. Fim de Século, Lisboa, 2006, p.140. 
ligação semântica, que trabalha no corpo, a hospitalidade tanto quanto a hostilidade: hostes, hospes, hostipet, posis, despotes, potere, polis sum, possum, pote est, potest, pot sedere, possidere, compos, etc ${ }^{31}$.

A hospitalidade reconhece, simultaneamente, o Outro-estranho, bem como o anfitrião. Não se ocultam. Jesus, em Betânia, não se ocultou, dialogou com Marta e Maria e chamou à atenção para a grande virtualidade da hospitalidade: "ouvir o hóspede". Toda a hospitalidade implica uma audição (Maria), devido a "ouvir o hóspede" (dom), uma decisão (Marta) vivenciada nas múltiplas tarefas (contra-dons) e, finalmente, uma "recitação" determinada, elpidicamente, por Jesus Cristo. Assim, a hospitalidade tornou-se condição do evento do Outro-estranho pela recitação. Eu decido, eu decido-me e, soberanamente, o que quer dizer o Outro de mim, o Outro-eu como Outro e como Outro de mim, faz ou faço excepção do mesmo. Para Derrida, a hospitalidade revela-se antes de mim. A hospitalidade pura, incondicional ou absoluta, é "primeira". A hospitalidade, pelo pensamento de Derrida, é um "por-vir", sendo uma Filosofia Primeira, a "ética da hospitalidade". Segundo a nossa perspetiva, a hospitalidade será "ouvir a palavra". A hospitalidade sucede-se como "acontecimento pístico".

Como refere Fernanda Bernardo, a experiência da pura hospitalidade, da hospitalidade incondicional, como um pólo de referência, indispensável e singularmente principal, manifesta-se como "desejo do desejo" ${ }^{32}$. Em Derrida, a Ética da Hospitalidade está não só, na sua imediatidade, imediatamente interrompida e contrariada pelo "terceiro", tal como acontece em Levinas, mas, um tanto ou quanto de forma diferente, porque uma tal imediata interrupção-contradição está, para além da sua condição de possibilidade, na contaminação, como comenta Fernanda Bernardo ${ }^{33}$. Daqui que a sua imediata interrupção-contradição é, igualmente, a sua natural interrupção-contradição ou "contaminação", como caracteriza Fernanda Bernardo. Surge como a sua condição de possibilidade ou a condição da sua "im-possibilidade" A hospitalidade é esta impossibilidade do possível, como "realidade incondicional".

31 Cf. DERRIDA, J, Le monolinguisme de l'autre, ou la prothèse d'origine. Éditions Galilée, Paris, 1996, p.27.

32 Cf. BERNARDO, F, “A etica da hospitalidade ou o por-vir do cosmopolitismo por-vir. (I.), p.411.

33

Cf. Ibidem.

34

Cf. Ibidem. 
A hospitalidades é um valor e vive de valores, até porque esta implica uma hierarquia de valores. É um "acolhimento axiológico".

Parece que uma tensão persiste entre estes dois pólos, o da incondicionalidade e o da condicionalidade, muito embora se dissociem, não alimentando qualquer oposição, nem cronologia. A anterioridade da Ética da Hospitalidade e da hospitalidade "em si” é uma anterioridade anterior ao tempo. Ela inaugura o tempo, inaugurando o "instituído ". A hospitalidade é uma implicação e uma impossibilidade do Outro. Segundo a interpretação de Fernanda Bernardo, pelo pensamento de Derrida, descreve-se que o Outro-único é incondicionalmente acolhido, seja em si próprio um estranho, seja uma singularidade plural e que a relação dual e dissimétrica, que acolhe, esteja, desde sempre, afetada e contaminada pelo terceiro, numa palavra, que a hospitalidade ética seja i-mediatamente "hos-ti-pitalidade", que ela esteja desde sempre, obrigada a deixar-se contaminar pelas leis da hospitalidade, é justamente o que é significado pela homonímia derridiana "tout autre est tout autre" (todo outro, será todo outro). Uma homonímia, que traça a contra-assinatura da Ética levinasiana, colocando em cena a sua dificuldade ou o seu carácter aporético. Uma homonímia que traduzimos assim: O Outro absoluto é absolutamente Outro, no sentido em que é uma "alteridade absoluta", e todo e qualquer Outro é absolutamente Outro, no sentido em que aparece como esta alteridade ${ }^{35}$. A hospitalidade é a implicação da alteridade. Desta forma, a hospitalidade manifesta-se como modalidade entre o possível e o impossível.

Em Betânia, Jesus Cristo é o Outro, como Outro, foi a "alteridade absoluta". Jesus Cristo é um Outro-absoluto, que vem e vai, que se hospeda, sem convite e sem dizer que chega. Jesus veio como hospitalidade absoluta em Betânia. Para Derrida, a incondicionalidade, que determina o acolhimento do Outro, do visitante, anónimo e inesperado, como "outro absoluto", ordena por esse primeiro acolhimento ético, como um acolhimento incondicional de todo e qualquer Outro. Tudo se passa como se a hospitalidade fosse impossível, como se a lei da hospitalidade definisse esta mesma impossibilidade, como se não pudessemos senão transgredi-la, como se a lei

35 Cf. MARGEL, S, Le tombeau du dieu artizan. Les Éditions de Minuit, Paris, 1995, pp.11-42. 
da hospitalidade incondicional, como se o imperativo categórico da hospitalidade ordenasse transgredir todas as leis da hospitalidade, a saber, as condições, as normas, os direitos e os deveres, que se impõem aos hóspedes, àqueles e àquelas, que se oferecem, assim como aqueles ou aquelas que recebem o acolhimento. Reciprocamente, tudo se passa como se as leis da hospitalidade consistissem em marcar limites, poderes, direitos e deveres, em desafiar e em transgredir a lei da hospitalidade, aquela que obrigaria a oferecer, ao recém-chegado, um "acolhimento sem condições" 36 . O acolhimento a Jesus Cristo, em Betânia, foi sem condições e sem limites por parte de Marta e de Maria. Foi uma hospitalidade absoluta, aquela que se passou em Betânia. Tratou-se, entretanto, de um "acolhimento desinteressado", de um "acolhimento agápico". Derrida segue os destinos aporéticos da hospitalidade, quando diz que incessantemente nos espreitará esse dilema entre, por um lado, a hospitalidade absoluta (incondicional), que excede o direito, o dever ou mesmo a política e, por outro, uma hospitalidade circunscrita ao direito e ao dever (condicional), uma pode sempre corromper a outra e esta pervertibilidade permanece irredutível ${ }^{37}$. Trata-se, pois, de um facto que trai a relação originária com o Outro, enquanto absoluto e único. Na sua incondicionalidade, a Ética da Hospitalidade está, naturalmente, obrigada a inscrever-se, comprometendo-se na inscrição das suas condições. Será por isto que Derrida não delimita a hospitalidade da hostilidade, o bem do mal e a não-violência da violência. Na verdade, parece que, segundo a desconstrução, não existe primeiro a hospitalidade e depois a hostilidade. Como descreve Fernanda Bernardo, a hostilidade absoluta é coisa, é a essência da Filosofia. Esta interdita ao contaminar imediatamente aquela. Entre elas não há sequência ou complementaridade, mas antes uma simultaneidade contaminada ${ }^{38}$. O valor da ética desconstrutiva, na hospitalidade, será possível como im-possível ou apenas vir a faltar? Derrida respondeu: será a impossibilidade de controlar, de decidir, de determinar um limite, a impossibilidade de situar, para nele se manter, através de critérios, de normas, de regras, o limiar, que separa a previsibilidade da perversão. Esta impossibilidade é necessária. Para que a hospitalidade incondicional seja viável, é necessário compreendê-la através da perspetiva desconstrutiva de uma ultrapassagem das oposições binárias metafísicas. A hospitalidade é, com efeito, um "passo" e uma aporia da desconstrução.

36 Cf. Ibidem, p.418.

37 Cf. DERRIDA, J, De l' hospitalité, Anne Dufourmantelle invite Derrida à répondre, p.119.

38 Cf. BERNARDO, F, “A etica da hospitalidade ou o por-vir do cosmopolitismo por-vir. (I.)", p.423. 
É preciso que este limiar não esteja à disposição de um saber geral ou de uma técnica regulada. É preciso que ele exceda todo o procedimento regulamentado para se abrir àquilo mesmo que ocorre, sempre que surja o risco de se perverter (o Bem, a Justiça, o Amor, a Fé e a Perfetibilidade). É preciso, isto é, precisa-se desta possível hospitalidade do pior, para que a boa hospitalidade tenha a sua oportunidade, a oportunidade de deixar vir o Outro, o sim do Outro, não menos que o sim do Outro ${ }^{39}$. Com efeito, a im-possibilidade da Ética da Hospitalidade é a condição de a subtrair, não só aos bons sentimentos, como também ao egoísmo e à normatividade. Uma tal Ética será, também, uma "metagnoseologia", estando para além do conhecimento, como salienta Fernanda Bernardo. Ela está antes do saber, antes de todo o socius,organizado por diante da politeia, antes de toda a lei. Logo, a hospitalidade incondicional vive de dois functores das lógicas modais, a saber: impossibilidade e necessidade,enquanto que a hospitalidade condicional é determinada por dois functores modais, isto é: possibilidade e contingência.

\section{4}

Entretanto, Kant formula o "direito cosmopolítico" (Weltbuergerrecht), mas não só o restringe às condições da hospitalidade universal, como também irá ditar, a esta, diversos limites. O pensador de Koenigsberg parece estender, sem limites, o direito cosmopolita à hospitalidade universal ${ }^{40}$. A hospitalidade, no âmbito da superfície da Terra, vive como algo de universal. Esta é uma condição da paz perpétua entre os homens, dado que, segundo Kant, "o estado de paz entre os que vivem juntos não é antes um estado de guerra, isto é, um estado em que, embora não exista sempre uma explosão das hostilidades, há sempre, no entanto, uma ameaça constante. Deve, portanto, instaurar-se o estado de paz; pois a omissão da hospitalidade não é ainda a garantia de paz e se um vizinho não proporciona segurança a outro (o que só pode acontecer num estado legal) cada um pode considerar-se como inimigo a quem the exigiu tal segurança”"41 , segundo citação de Derrida, relativamente ao pensamento kantiano. O direito cosmopolita à hospitalidade universal, como condição da paz

39 Cf. Ibidem, p.434.

40 Cf. KANT, I, Zum ewiegen Frieden, KANT's Werke, Abhandlungen nach 1781. Koeniglich Preussischen Akademie der Wissenschaften, Band VIII, Walter de Gruyter \& Co., Berlin, 1923, pp.348-349.

41 DERRIDA, J, Cosmopolites de tous les pays, encore un effort! Éditions Galilée, Paris, 1997, pp.53-54. 
perpétua, entre todos os homens, afigura-se, para Kant, como um direito natural e aparece como direito instituído. Na linha de Kant, a hospitalidade condicional fundamenta-se na "lei natural" (ratio insita in natura). A hospitalidade da cidade ou a hospitalidade privada são dependentes e controladas pela lei e pela política do Estado, tal como comenta Derrida pelo seguinte pensamento: "Se Kant faz questão de precisar que este bem ou este lugar comum se estende à "superfície da terra" é, sem dúvida, para não lhe subtrair nenhum ponto do mundo ou de um globo esférico e finito (mundialização e globalização), ali onde uma dispersão infinita é impossível; mas é sobretudo para excluir o que se ergue acima do solo: habitat, cultura, instituição, Estado, etc. Tudo quanto, incluindo o solo, não é mais o solo e, ainda que fundado na terra, não deve ser incondicionalmente acessível a todo o "recém-chegado". Graças à condição desta estrita delimitação (que não é senão a instituição do limite como fronteira, nação, Estado, espaço público ou político), Kant pode então deduzir duas consequências e inscrever outras duas grelhas sobre as quais teríamos interesse em refletir futuramente" ${ }^{\text {"æ2 }}$. A hospitalidade incondicional é de lei natural, as hospitalidades condicionais pertencem ao direito positivo.

As duas grelhas são: 1 - Em primeiro lugar, o filósofo de Koenigsberg exclui a hospitalidade como direito de residência (Gastrecht), limitando-o ao "direito de visita", dado que o anterior direito deveria ser objeto de um tratado particular entre os estados, 2 - A seguir, definindo, com todo o rigor, a hospitalidade como um direito, Kant determina as condições que o fazem depender da soberania estatal, particularmente quando se trata do "direito de residência". A hospitalidade da cidade ou a hospitalidade privada são dependentes e são controladas pela lei e pela polícia do Estado, como comenta Derrida ${ }^{43}$.

Desta feita, a hospitalidade kantiana será uma hospitalidade universal, tratando-se, como é, de uma hospitalidade jurídico-política. É uma hospitalidade dada a partir da polis (cidade-estado), que, segundo o pensamento de Derrida, se poderá chamar de "condicional". Uma vez que a hospitalidade é um direito dado ou recusado ao cidadão-estrangeiro, determinada pela soberania do Estado. Surge, então, como acolhimento condicional. O ideal da hospitalidade cosmopolita está ligado a uma figura da cidadania, do Estado-nação, supondo que o cidadão seja cidadão do mundo, enquan-

42 Ibidem, pp.54-56.

43 Cf. Ibidem, pp.14-15. 
to cidadão, isto é, enquanto sujeito de um Estado-nação. Aqui temos o exemplo do que é uma hospitalidade condicional. A partir daqui define-se um conceito inédito de hospitalidade, como refere Derrida, em Cosmopolites de tous les pays, encore un effort!, pelas seguintes palavras:" Quer se trate do estrangeiro em geral, do imigrado, do exilado, do refugiado, do deportado, do apátrida, da pessoa deslocada (tudo categorias a distinguir prudentemente), convidamos estas novas cidades-refúgio a infletir a política dos Estados, a transformar e a refundar as modalidades de pertença da cidade ao Estado, por exemplo, numa Europa em formação ou em estruturas jurídicas internacionais, ainda dominadas pela regra da soberania estatal, regra intangível ou suposta como tal, mas também regra cada vez mais precária e problemática. Esta não pode nem deveria mais ser o horizonte último das cidades-refúgio. Será possível? Ao comprometermo-nos, ao convidar metrópoles e cidades modestas a comprometerem-se nesta via, ao escolher para elas este nome de "cidades-refúgio", quisemos sem dúvida mais do que uma coisa, como aconteceu com o nome "parlamento". Ao reativar o sentido tradicional de uma expressão e ao despertar para a sua dignidade uma herança memorável, quisemos ao mesmo tempo propor, sob o velho nome, un conceito inédito de hospitalidade, do dever de hospitalidade e do direito à hospitalidade" ${ }^{\text {"44 }}$. Aquilo que, revelando embora a impotência, a insuficiência e a injustiça do Estado, de uma certa ideia de Estado, de uma certa política do Estado e de uma certa hospitalidade inter-estatal-nacional, não deixará de revelar uma das dimensões da sua necessidade.

Qualquer forma de hospitalidade, quer condicional, quer incondicional, surge como Ética, dado que a Ética é Hospitalidade. Ela será, de todo em todo, co-extensiva à experiência da hospitalidade. Daqui se infere que o "l'être-soi chez soi" supõe um acolhimento ou uma inclusão do Outro, na procura de se apropriar, controlar e orientar, segundo diferentes modalidades de violência, existindo uma história de hospitalidade, uma perversão sempre possível da Lei da Hospitalidade, tal como comenta Derrida:" Na medida em que ela diz respeito ao ethos, a saber, à morada, à casa própria, ao lugar da residência familiar assim como ao modo de nela estar, pelo modo de se relacionar consigo e com os outros, com os outros como com os seus ou como com estrangeiros, a "ética é hospitalidade", ela é de parte a parte co-extensiva à experiência da hospitalidade, seja qual for o modo como se abra ou se a limite. Mas, por esta mesma razão, e porque o ser-se si mesmo em sua casa (a própria ipsei-

44 Cf. Ibidem, pp.42-43. 
dade) supõe um acolhimento ou uma inclusão do Outro, que se procura apropriar, controlar, dominar, segundo diferentes modalidades da violência, há uma história da hospitalidade, uma perversão sempre possível d'A lei da hospitalidade (que pode parecer incondicional) e das leis que a vêm limitar, condicionar, inscrevendo-a num direito..." ${ }^{45}$. Com a pretensão de lutarem contra uma imigração económica, disfarçada de exílio, ou, em fuga, perante a perseguição política, os Estados rejeitam, mais do que nunca, os pedidos de asilo, como salienta Fernanda Bernardo. Desta forma, mudar esta regra, denunciando a injustiça profunda, será uma regra sem regra, que a nova Ética, enquanto "idioma da desconstrução", se propõe alcançar, que, além do repatriamento, deseja abrir um novo direito e uma nova política, segundo a hospitalidade, surgindo um novo cosmopolitismo.

A Ética da Hospitalidade será uma espécie de vigília provocadora, que mantém o “por-vir” do cosmopolitismo. Será um esforço decisivo, pedido por Derrida à hospitalidade, inter-estadual-nacional, que será um "passo" a seguir ${ }^{46}$. Teremos um passo, a mais, exigido às leis da hospitalidade, uma vez que se manifesta como um passo a mais do que é exigido. Este passo, a mais, é um passo para além das leis da hospitalidade. É um "meta-passo" ou um "hiper-passo". Este "hiper-passo" chama-se hospitalidade. Logo, um tal passo leva a acabo o desejo de retidão, sendo, também, um passo de interrupção e de transgressão das leis da hospitalidade; aquelas que, no âmbito da tradição greco-latina, do direito e da filosofia, distanciam o dever e o direito na hospitalidade através da família, da sociedade civil e do Estado, ou seja, através da cidadania, no dizer de Fernanda Bernardo ${ }^{47}$. Será um passo que traduz, secundum quid, a necessária inscrição da lei da hospitalidade, revelando o carácter paradoxal da hospitalidade, no domínio do pensamento derridiano, constituindo, na verdade, um carácter que dá conta da heterogeneidade existente entre a lei e as leis da hospitalidade ${ }^{48}$.

45 Cf. DERRIDA, J, De l' hospitalité, Anne Dufourmantelle invite Derrida à répondre, p.131. 
A hospitalidade é um "passo", quer plesiológico (relações entre o anfitrião e o homo mendicans), quer soteriológico, como se descreve na narrativa, segundo Lucas, dos discípulos de Emaús, referindo-se como narrativa sobre a hospitalidade de convite. A lei da hospitalidade constitui um "pólo absoluto", fora do qual o desejo, o conceito, a experiência e o próprio pensamento da hospitalidade não teriam qualquer sentido. $\mathrm{Na}$ verdade, será um pólo absoluto, que é precisamente o lugar a partir do qual são ditadas as oportunidades concretas, exigindo respostas.

Com efeito, esta "lei anónima" precisa de se instaurar nas leis da hospitalidade, a fim de ganhar atualização e obter realização, tal como salienta Fernanda Bernardo. A lei da hospitalidade necessita de se "desviar da retidão," instaurando-se nas leis condicionais da hospitalidade (leis positivas), tornando efetiva a hospitalidade incondicional. Esta inscrição da lei de hospitalidade, nas leis, é uma inscrição, que permite distinguir um hóspede de um intruso, assegurando-lhe as condições de acolhimento, para não haver transgressão da lei da hospitalidade. Será uma interrupção das leis da hospitalidade que, como analisa Derrida, deixariam de ser leis da hospitalidade, se não fossem guiadas pela lei da hospitalidade incondicional . Naturalmente, a inscrição da lei da hospitalidade é a condição do seu progresso e do seu processo ${ }^{49}$. Aqui temos a dependência da hospitalidade condicional. Necessita, para se fundamentar, da hospitalidade incondicional. A hospitalidade condicional é uma possibilidade da hospitalidade incondicional, uma vez que a lei transgride as leis, mas uma tal transgressão orienta o rumo para uma justa perfetibilidade. A hospitalidade condicional, segundo Derrida, atinge o seu aperfeiçoamento na hospitalidade incondicional. A hospitalidade condicional poderá contaminar-se. A lei da hospitalidade é um princípio de resistência absoluta, obrigando ao impossível. Como se expressa Fernanda Bernardo, sendo inspiradas, afetadas, interrompidas ou espetralizadas pela Lei da Hospitalidade incondicional, as leis da hospitalidade não são a Lei da Hospitalidade. Entenda-se, segundo Derrida,não são mais as político-jurídicas da hospitalidade, aquelas cujo plural é feito de uma multiplicidade, diferenciação e distribuição de leis e cuja fórmula algébrica seria $n+n+n, \ldots$

49 Cf. DERRIDA, J, De l' hospitalité,Anne Dufourmantelle invite Derrida à répondre, p.131. 
Diferentemente, a gramática deste estranho plural, deste singular plural das leis da hospitalidade significa a adição antinómica das leis da hospitalidade à lei da hospitalidade. Um tal plural recorda o perfil ético-político-jurídico das leis da hospitalidade, ou seja, a inscrição da lei da hospitalidade, única, singular e absoluta nas leis. Há um perfil que, salientando muito embora a impossibilidade da Lei da Hospitalidade e, ipso facto, a inevitabilidade da contaminação da Ética da Hospitalidade, pelo aspeto político-jurídico, revela a reinvenção do político e do jurídico. Logo, a hospitalidade condicional será a restauração da hospitalidade incondicional, sendo reinventada pela Ética da Hospitalidade. Sob o ponto vista ético-politico, o pensamento derridiano aponta para uma convivência tolerante - a hospitalidade - e seus motivos parecem ser mais fortes que aqueles que sustentam a hostilidade entre os seres humanos. Este pensamento refere-se à possibilidade de um Estado democrático "por-vir", ainda que a ambivalência hospitalidade/hostilidade permaneça. Derrida apresenta, segundo comentário de Maia Soares, sérias reservas quanto à palavra "tolerância" e quanto ao discurso organizado por ela. A tolerância surge como uma hospitalidade condicional, circunspecta, cautolosa. Na hospitalidade incondicional não existe a tolerância, dado que esta não é uma virtude. A tolerância poderá estar presente na hospitalidade condicional, tal como se vivencia na política, no direito ou na economia.

$\mathrm{Na}$ verdade, o novo cosmopolitismo anuncia-se como promessa de uma justa hospitalidade, como aquela que se expõe sem limites. Por causa das duas formas de hospitalidade (condicional e incondicional), não há uma hospitalidade-modelo, antes é necessário a cada passo, isto é, na urgência de cada caso "reinventá-la". Isto quer dizer, então, que não haverá uma hospitalidade hiperbólica, tal como descreve Derrida, ao aplicá-la à hospitalidade abrahamica, visto que as narrativas patriarcais do Genesis são folclóricas e prefigurativas do Novum Testamentum (Nova Aliança), segundo a Teoria da Literatura Bíblica. Assim, a hospitalidade deverá ser uma permanente invenção. Cria-se e recria-se. A hospitalidade é imediatamente perfetível, não existindo uma hospitalidade-modelo,mas antes processos em vias de se perverterem e de melhorarem ${ }^{50}$. As duas formas de hospitalidade complementam-se, sendo uma o lado contemplador da hospitalidade (incondicional) e a outra o lado pós-ético da hospitalidade (condicional). A hospitalidade condicional é não separada e finita. É uma hospitalidade concreta "de convite". A esta hospitalidade acrescenta-se uma

50 Cf. BERNARDO, F, “A etica da hospitalidade ou o por-vir do cosmopolitismo por -vir (I.)”, pp.444-445. 
condição, pergunta-se pelo Bilhete de Identidade. É uma hospitalidade impura. A hospitalidade condicional refere o acolhimento ocasional do dia-a-dia. Interpretando o pensamento de Derrida, a hospitalidade condicional é uma hospitalidade de identidade, enquanto que a hospitalidade de alteridade estará ligada à incondicional, muito embora poderá ligar-se à condicional. Foi o que aconteceu com o Desvalido no Caminho (Jesus Cristo), que, tendo sido entregue ao estalajadeiro, segundo o conto provocante do Bom Samaritano (Lc 10,35), realizou uma "hospitalidade condicional". Com efeito, segundo a parábola, o Samaritano realizou a hospitalidade de alteridade, em detrimento da hospitalidade de identidade, simbolizada pelas atitudes do Sacerdote e do Levita (Lc10, 31-32).

Derrida estabelece a distinção entre hospitalidade de visitação e a de convite em États d'âme de la psychanalyse. Segundo Derrida, a nossa questão será de identidade, como forma de "ipseidade" perante o Outro-estranho, esse Outro que é recebido como Outro, como um todo e como alguém que é o Outro do Outro. A hospitalidade passa inevitavelmente pelo regresso à singularidade do Outro, numa cena de dualidade assimétrica e porque um tal endereço compreende sempre os outros. Há uma grande diferença entre as duas hospitalidades, dado que a incondicional consiste em acolher Outrem, antes de lhe colocar qualquer condição, antes mesmo de lhe perguntar pelo nome ou pelo número. Todavia ela supõe, também, que nos enderecemos singularmente a ela, que chamemos o hóspede pelo nome, que lhe reconheçamos um nome próprio, o qual apesar da sua contaminação é o índice da sua inamovível singularidade. Mas, a hospitalidade pura consiste em acolher "o recém-chegado", antes de lhe colocarem condições, antes de saber e de lhe pedir o que quer que seja, sendo mesmo o seu nome ou um bilhete de identidade ${ }^{51}$. Toda a hospitalidade pura, por oposição à impura, refere um "acolhimento do outro", sem condições e sem questões, comportando uma ameaça intrínseca, uma perversão, enquanto que a hospitalidade condicional não determina uma perversã $0^{52}$. As normas inventam-se, em cada situação concreta, implicando a condicionalidade num "acolhimento incondicional" do recém-chegado, seja ele quem for. Uma tal invenção é o espírito da "hos-ti-pitalidade", rosto do cosmopolitismo e da hospitalidade condicional, que se confunde com a nova internacional, aquela cujas alianças se firmam a partir do acolhimento singular do visitante inesperado. Aqui está o sentido da hospitalidade condicional, que su-

51 Cf. DERRIDA, J, États d'âme de la psychanalyse. Éditions Galilée, Paris, 2000, p.40.

52 Cf. DERRIDA, J, Papier Machine, p.275. 
põe a incondicional. Estes dois pólos (condicional e incondicional) são indissociáveis, sendo heterogéneos e manifestam-se como irredutíveis um ao outro, como nos diz Derrida $^{53}$. O tema da hospitalidade concentra, hoje-em-dia, as urgências mais concretas e as mais adequadas para articular a Ética à Política ${ }^{54}$. Será necessário fazer tudo para que as leis da hospitalidade se inscrevam na lei positiva, sendo quase impossível pensar aquilo que é necessário fazer contra as leis. Com esta perspetiva de Derrida, surgiu, na relação de incondicionalidade e de condicionalidade da hospitalidade, segundo Fernanda Bernardo, um novo Direito e uma nova Ética. A hospitalidade manifesta-se, quer de forma condicional, quer de forma incondicional, como essência do "être-soi" (ser em si) ou da "ipseidade", como aquela que identifica a lei na língua materna . A hospitalidade sempre foi a essência do "chez soi" (em sua casa). É a essência da casa. O sentido da hospitalidade condicional está definido pelos direitos e pelos valores do convite. A hospitalidade condicional encontra-se vivenciada no asilo, nos direitos e nos não-direitos dos estrangeiros. Será, naturalmente, uma maneira de tirar algumas consequências éticas, jurídicas e políticas.

A hospitalidade concentra amizades, uma vez que ela está dedicada ao "por-vir" da esperança. Ensina-nos a viver juntos, permitindo dizer que é uma esperança. É uma relação de Outros, em que um se manifesta ao Outro e vive para o Outro. A hospitalidade recria-se no Outro, num Outro que é acolhido. Assim, a hospitalidade é o grande "passo" ou "passagem (Pascha) da proximidade e da criação do "espaço plesiológico". Esta é uma novidade da hospitalidade trazida pelo conto do Desvalido no Caminho (Lc10,25-37).

\section{6}

Jesus Cristo recriou-se, no acolhimento de Betânia, com Marta e Maria, ao “ouvirem as palavras". Toda a hospitalidade terá uma ou várias dimensões elpídicas, como se vivenciou no castellum de Betânia (Lc 10,38-42). A hospitalidade implica uma determinada forma de se tornar no Outro, como Outro, sendo o "reconhecimento do Outro", que tanto pode estar na hospitalidade absoluta, pura e incondicional, quanto manifestar-se na hospitalidade condicional. Poderemos dizer que a hospitali-

53 Cf. DERRIDA, J, Voyous, Deux essais sur la raison, p.95.

54 Cf. BERNARDO, F, “A etica da hospitalidade ou o por-vir do cosmopolitismo por -vir (I.)”, p.445. 
dade é a perfectionis amicitiae splendor (esplendor da perfeição da amizade). Todo o conceito de hospitalidade é, naturalmente, polissémico, como forma de vivenciar a mesma num todo fenomenológico. A hospitalidade vive numa "fenomenologia elpidofânica", que começa na espera/esperança e termina no reconhecimento e/ou "acolhimento agápico ", que tem o seu eco na hospitalidade de Betânia. Certamente que um bom exemplo do que foi a hospitalidade condicional estará nas condutas do Sacerdote e do Levita, segundo a parábola do Desvalido no Caminho. Esta conduta definiu-se num "amor de identidade", que fora próprio da hospitalidade condicional. Na verdade, a hospitalidade absoluta (acolhimemto do acolhimento) revela-se como um "amor de alteridade", ora simbolizado no Samaritano (Lc 10,33), ora, em Cristo, na hospitalidade de des-construção de Betânia. Nesta hospitalidade, Jesus Cristo "desconstruiu" as condutas, quer de Marta, quer de Maria. Jesus Cristo foi a "desconstrução da desconstrução", em sentido agápico, e não com valor filico, como é descrito pelo pensamento aristotélico. O "amor de identidade" começa, logo, na conduta do vоцıкó (Doutor da Lei), que ficara a saber, provavelmente, mais do que queria "fazer" e menos do que queria saber. Mas, ficara a "saber" aquilo que "fazer" para ser "próximo" de alguém. Permaneceu na sua "identidade", porque poderá não ter ficado a saber quem era o verdadeiro próximo, o único que nos pode fazer próximos. Até porque as duas perguntas do "legista" não parecem ser inocentes, uma vez que a primeira é para $\varepsilon \kappa \pi \varepsilon \iota \rho \dot{\alpha} \zeta \omega v$ (experimentar) Jesus (Lc 10,25) e a segunda é para se justificar a si mesmo, afirmando a sua "identidade" $(\operatorname{Lc} 10,29)^{55}$. O Sacerdote e o Levita são, na parábola, a expressão do viver a partir do livre curso dos desejos, projetos e instintos, procurando dominar o Outro para o pôr ao seu serviço. Estes dois personagens, no seu fazer ritual, definem uma hospitalidade condicional. Um exemplo de vivência neotestamentária da hospitalidade por convite, ou melhor de "autoconvite", encontra-se expressa no encontro de Zaqueu com Jesus Cristo. Zaqueu, em Jericó, subiu a um sicómero para melhor ver Jesus, que por ali passava: "quando Jesus chegou ao lugar, levantou os olhos e disse: Zaqueu, desce depressa, pois hoje devo ficar em tua casa" $(\text { Lc 19,5) })^{56}$. Aqui está a hospitalidade por convite e o convite da hospitalidade. Zaqueu recebeu-O, em sua casa, chamando-lhe Senhor, declarando, com alegria, de pé, que daria metade dos seus bens aos pobres (Lc

55 Cf. BORGES DE MENESES, R. D, O Desvalido no Caminho. O Bom Samaritano como paradigma da humanização em saúde, Edições Passionistas, Santa Maria da Feira, 2008, pp. 24-69.

56 Cf. NESTLE-ALAND, Novum Testamentum Graece et Latine, Deutsche Bibelgesellschaft, Stuttgart, 1994, p.222. 
19,8). Por sua vez, os discípulos de Emaús reconhecem Jesus na "fração do pão" (Lc 24,31). No caminho, que ligava Jerusalém a Emaús, caminhavam dois discípulos: "Jesus aproximou-se e pôs-se a caminhar com eles" (Lc24,15). Os discípulos não O reconheceram. Mas, aproximando-se do povoado, eles insistem com o Outro-estranho: "Permanece connosco, pois cai a tarde e o dia já declina" $(\operatorname{Lc} 24,29)^{57}$. Aqui encontra-se simbolizada a "hospitalidade por convite".

Assim se descreve a hospitalidade condicional, segundo a terminologia derrideana, pelos referidos relatos neotestamentários.Toda a hospitalidade, como transparece pela Sagrada Escritura,quer pelo Primeiro, quer pelo Segundo Testamentos, surge como uma vivência aretológica, onde reside o primado da excelência das condutas entre um anfitrião e um homo mendicans.

\section{Conclusões}

a. A hospitalidade condicional é per accidens. Surge como in vita contingens maxime (maximamente contingente na vida). Na verdade, a hospitalidade condicional estará ligada a uma hospitalidade "por convite", tal como a abrahamica, narrada no livro do Genesis (18,1-15). Abraham significou, ao receber os "três visitantes misteriosos", uma forma de hospitalidade de prefiguração, entre a condicional e a incondicional, sendo a síntese das duas anteriores. Surge, de facto, uma "hospitalidade ética", para usar a terminologia de Derrida. Com efeito, trata-se de uma hospitalidade, que vai da sociologia ao direito, passando pela política, sem esquecer a filosofia. A hospitalidade condicional é uma hospitalidade acidental, podendo descrever-se como hospitalidade de ocasião, porque não é permanente, estando dependente do "convite". É o "convite" do anfitrião ao Outro-estranho. Há um esse ad vivencial entre o anfitrião e o Outro-estranho, que será acolhido. Influenciados, pela desconstrução dos textos dos sinópticos, poderíamos apresentar uma nova tipologia classificativa, segundo a hospitalidade, em hospitalidade de identidade e hospitalidade de alteridade;

57 Cf. Ibidem, pp.243-244. 
b. O acolhimento do acolhimento reside nesta hospitalidade absoluta. Finalmente, diremos que a hospitalidade incondicional é acolhimento per se. A hospitalidade pura ou incondicional, a hospitalidade em si, abre-se para alguém, que não é esperado nem convidado, para quem quer que chegue, como um visitante absolutamente estranho, não identificável e imprevisível, ou seja, "totalmente outro". Desta sorte, a questão da hospitalidade está, pois, ligada à questão da diferença. Não às diferenças excludentes, como são os nacionalismos e os fanatismos religiosos, mas ao "deixar vir o outro", respeitando a sua multiculturalidade em seus diferentes matizes, aceitando as diferenças, enquanto diferentes. Poderemos dizer que a hospitalidade incondicional se determina como in vita maxime necessarium (maximamente necessária na vida). Esta será, para Derrida, a hospitalidade como "primeira", que estará "antes de mim", da minha liberdade (Kant) ou da minha consciência (Descartes). A hospitalidade incondicional será a incondicionalidade do Outro-estranho no anfitrião e vice-versa. A hospitalidade incondicional revela-se como o acolhimento do acolhimento. Será a "soberania do acolhimento" e a "sabedoria do acolhimento". Toda a hospitalidade, como se manifestou no acolhimento de Betânia, surge como uma "relação de relações plesiológicas" de um Senhor (anfitrião) com um súbdito (homo mendicans). A hospitalidade é uma "soberania" que está "por-vir". É o acolhimento, em casa, do Senhor para com o súbdito, e, vice-versa., porque qui venturus est. Por isso, toda a hospitalidade é Ética, como vida, como cultura, como um "talvez" do acolhimento. A hospitalidade é uma outra Ética. Uma das visualizações da hospitalidade é oferecida pelo acolhimento em saúde, que caracteriza a humanização hospitalar. Um dos seus aspetos terá a ver com a incondicionalidade da hospitalidade, uma vez que a humanização em saúde é uma hospitalidade, o acolhimentio clínico poderá ser incondicional, sem convite. Mas também poderá ser condicional. As patologias e as exigências diagnósticas impelem per essentiam suam a uma hospitalidade clínica, particularmente pelos cuidados primários. O doente é um "recém-chegado" sem condições. Assim, o acolhimento clínico (relação médico-doente) é determinado por uma "desconstrução incondicional", que se denomina "hospitalidade incondicional" na humanização em saúde;

c. A hospitalidade é um "acolhimento poiético", porque exige uma "espera", que é preparação para o acolhimento. Esta hospitalidade é "elpídica", uma vez que há uma conversão àquilo que "há-de vir". A hospitalidade é um "Zukunft" elpidofâ- 
nico do acolhimento do Outro, tal como Jesus se acolheu com Marta e Maria. A hospitalidade é uma recitação elpídica do Outro. O Outro acolhe-se! É recitado pela espera do anfitrião. A recitação elpídica é a hospitalidade e esta supõe, dialeticamente, a audição (contemplação da Palavra) e a decisão (ação agápica). Maria traduz a audição, ao estar sentada aos pés da Palavra (Jesus Cristo), para alcançar a "decisão", que será o amor ao próximo ${ }^{58}$. Aquela que escolheu a melhor parte, foi a mais hospitaleira. Segundo a hospitalidade, que Marta signifique a vida ativa e Maria a vida contemplativa, são estereótipos funcionais para referir uma leitura eclesiástica, que estabeleceu os dois destinos destas mulheres de Betânia. São necessárias poucas coisas, mesmo uma só coisa. Há a vantagem de dar ao episódio a conclusão mais profunda: a palavra de Jesus ultrapassa toda a preocupação temporal ou "solicitude telúrica", como também se verifica em At 6,2. A exegese posterior encontrará aqui a proclamação da superioridade da "contemplação" sobre a "ação". Neste texto, sobre a hospitalidade de Betânia, não se trata de contemplar, mas antes de "escutar a Palavra", que chama à fé e à adesão da mesma . A hospitalidade é uma escuta da Palavra e a Palavra é Jesus Cristo. A primeira hospitalidade de Deus-Pai foi a criação do Universo e do Homem e a sua segunda solicitude foi uma preocupação soteriológica, que é Jesus Cristo no Gólgota. Assim, a hospitalidade implica uma "qualidade staurológica" (o acontecimento da Cruz). Na hospitalidade, há uma "solicitude poiética" que significa a prioridade que se dá ao Outro. Mas este é um acolhimento, que vai da escuta à contemplação do Outro. Segundo o livro de Levítico, Deus diz que a Terra é minha, Vós sois, para mim, estrangeiros e hóspedes (Lv 25,1-7). Nela poderemos habitar com consciência de quem vive hospedado (toshavim = inquilino, hóspede) $)^{59}$;

d. A solicitude exige um "espaço hospitaleiro", onde não é possível a lógica da apropriação, nem pronunciar o verbo "haver", nem o possessivo "meu". A hospitalidade é a linguagem e a mundividência do acolhimento, a língua do espanto e do reconhecimento. O paradigma profundo da "terra da promessa" está na revelação e na instituição deste espaço hospitaleiro, como espaço originário do ser humano. É um espaço onde se tem tudo, sem se possuir nada. É um espaço de hospitalidade.

58 Cf. BOVON, F, El Evangelio según San Lucas, II, Tradução do francês por Alfonso Ortiz Garcia. Ediciones Sígueme, Salamanca, 2002, pp.136-145. 
A figura que, no Novo Testamento, assume, em plenitude, a lógica da gratuidade, em contraste com o paradigma adâmico, é Cristo. Ele é o verdadeiro "espaço hospitaleiro", não pela Incarnação, mas pela Ressurreição, como dádiva, gratuidade perene e solicitude indivisível. A hospitalidade é uma procura de preocupação pelo Outro, que nos visita. Entra na nossa moradia. É um estranho. Logo, nascem em nós os sentimentos do acolhimento. Este sentimento presta-se à criatividade, que determina uma abertura ao Outro e ficamos no "desejo do Outro", que é conceito de hospitalidade segundo Levinas;

e. Finalmente, dizer que a cidadania é um espaço de hospitalidade, caracterizado por uma hospitalidade de alteridade. O exercício da cidadania constitui-se como exercício de hospitalidade. Com efeito, a verdadeira cidadania é aquela que se fundamenta na filosofia prática,chamando-se hospitalidade condicional, porque se mostra e declara como condicionalidade axiológica da hospitalidade. Se toda a cidadania vive como uma axiologia, então terá a ver com os graus de hospitalidade, desde a hospitalidade de identidade, até à hospitalidade de alteridade, como máximo grau de hospitalidade, segundo a nossa reflexão crítica. A cidadania, ao caracterizarem-se como os direitos e os deveres, a fim de habitarem a polis (cidade), fundando-se no direito positvo, surge como hospitalidade condicional, finita, impura, através do pendsamento de Derrida. Todavia, segundo a nossa posição, a cidadania é uma hospitalidade, ora de identidade (política, jurídica, económica, etc.), ora de alteridade (ética, axiologia, fenomenologia, etc.). O cidadão é hóspede na cidade, da cidade e para a cidade. Pois, aquele que está no gozo dos direitos civis e políticos, dum Estado, está na hospitalidade condicional da polis. 


\section{Bibliografía}

Bernardo, Fernanda. A etica da hospitalidade ou o por-vir do cosmopolitismo por -vir. (I.), Revista Filosófica de Coimbra, 10, 20, pp.333-426, 2001

A ética da hospitalidade, segundo J. Derrida, ou o porvir do cosmopolitismo por vir a propósito das cidades-refúgio. Re-inventar a cidadania (II) Revista Filosófica de Coimbra, 10, 21, pp.421-446, 2002

Para além do Cosmopolitismo kantiano:Hospitalidade e altermundialização ou a Promossa da nova Inter-nacional democrática de Jacques Derrida, Revista Portuguesa de Filosofia, 61, 3-4 , pp.951-1005, 2005

. Levinas e Derrida: contacto no coração de um quiasma, in: Revista Filosófica de Coimbra, 33, pp.38-78, 2008

Borges De Meneses, Ramiro Délio. O Desvalido no Caminho.O Bom Samaritano como paradigma da humanização em saúde. Santa Maria da Feira: Edições Passionistas, 2008 .

Borradori, Giovanna. Filosofia em tempo de terror: diálogos com Habermas e Derrida. Rio de Janeiro: Jorge Zabac, 2004

Bovon, Françors. El Evangelio según San Lucas, Vol.II, Tradução do francês por Alfonso Ortiz Garcia. Salamanca: Ediciones Sígueme, 2002

Chérif, Mahmoud. Islam et l'Occident, rencontre avec Jacques Derrida, Paris: Odile Jacob, 2006

Derrida, JACques. De 1' hospitalité,Anne Dufourmantelle invite Derrida à répondre. Paris: Calmann-Levy, 1977

. Voyous, Deux essais sur la raison. Paris: Éditions Galilée, 2003

. HABERMAS, J. Le concept du 11 septembre. Paris: Éditions Galilée, 2004

. Aporias.Morir-esperase (en) los limites de la verdad, Tradução do francês. Barcelona: Paidós, 1998

- Manifeste pour l'hospitalité. Paris: Éditions Paroles d'Aube, 1999 . Le toucher, Jean-Luc Nancy. Paris: Éditions Galilée, 2000 . ROUDINESCO, E. De quoi demain,... Dialogue. Paris: Éditions Galilée, 2001

. Papier Machine. Paris: Éditons Galilée, 2001

. Manifeste pour l'hospitalité. Paris: Éditions Paroles d'Aube, 1999 
. FERRARI,M., O Gosto do Segredo,Tradução do francês por Miguel Serras Pereira. Lisboa: Fim de Século, 2006

. Le monolinguisme de l'autre, ou la prothèse d'origine. Paris: Éditions Galilée, 1996 Cosmopolites de tous les pays, encore un effort! Paris: Éditions Galilée, 1997 . États d’âme de la psychanalyse. Paris: Éditions Galilée, 2000

- STIEGLER,B. Échographies de la télévision, Entretiens filmé. Paris: Éditions Galilée, 1996

Fornari-Carbonell, Isabel. La Escucha del Huésped (Lc 10,38-42): la hospitalidad en el horizonte de la comunicación. Navarra: Editorial Verbo Divino, 1995

Kant, Immanuel. Zum ewiegen Frieden, KANT's Werke, Abhandlungen nach 1781, Koeniglich Preussischen Akademie der Wissenschaften, Band VIII. Berlin: Walter de Gruyter \& Co., 1923

Maia Soares, Victor Dias. Hospitalidade e Democracia por-vir a partir de Jacques Derrida, Ensaios Filosóficos, 2 ,pp.175-180, 2012

Margel, Serge. Le tombeau du dieu artizan. Paris: Les Éditions de Minuit, 1995

Nestle-Aland. Novum Testamentum Graece et Latine. Stuttgart: Deutsche Bibelgesellschaft, 1994 